\title{
Brasil: the leading public kidney transplant program worldwide
}

(Denato Demarchi Foresto
José Osmar Medina Pestana
(D) Hélio Tedesco Silva Jr ${ }^{2}$

1. Hospital do Rim, São Paulo, SP, Brasil. 2. Hospital do Rim, Universidade de São Paulo, São Paulo, SP, Brasil.

E-mail:rdforesto@gmail.com
Brasil started its kidney transplant program in 1964, 10 years after the historic successful kidney transplant performed by Peter Medawar in Boston ${ }^{1,2}$. In the following years, kidney transplants in Brasil began to be carried out in university hospitals, but still without a large national organization. In the 1980s, the foundations for a stronger national kidney transplant program were laid with the creation of the Brazilian Association for Organ and Tissue Transplantation (ABTO) and a universal public health program (Unified Health System). Since then, many efforts have been made to develop the Brazilian kidney transplant program, such as detailed logistics for organ allocation, adequate reimbursements, and regular revisions in regulatory and legislative policies ${ }^{3,4}$.

The Brazilian transplant program reimbursement and organization promoted it as the largest public kidney transplant program worldwide, with fair organ allocation logistics based on HLA compatibility and no cultural or social prerogatives. This scenario allowed more than $95 \%$ of the transplants to be performed by the public system in Brasil, also including outpatient and hospital care, as well as providing every medication used in the long transplant follow-up free of charge5. The other $5 \%$ of transplants are performed in private institutions, which are also regulated and monitored by the government.
The national transplant system coordinates organ procurement/allocation and regulates transplant centers. Organ procurement organizations and hospital commissions are strategically spread throughout the national territory, although wide regional disparities still exist in Brazil ${ }^{4}$. The allocation system is primarily based on HLA compatibility within regional waiting lists. Brazilian legislation allows only brain-death donation after family consent for deceased donor kidney transplant, donation after circulatory death is still prohibited. For living donation, parents and spouses are allowed and unrelated donors need an ethical and judicial authorization ${ }^{3}$.

The impact of transplant legislation and investments was remarkable soon after the Unified Health System foundation in 1988. In the first period of the Brazilian kidney transplant program (1964-1988), 6,808 kidney transplants were performed. Within the following period of just 5 years (1989-1993), 6,578 patients received a kidney allograft, reaching 28,629 in the last period (2014-2018), with an accumulated number of 107,989 kidney transplants performed in Brasil. The use of kidneys from deceased donors was uncommon in the first 25 years (around 20\%), but the increase of effective deceased donors and tighter regulation for living donors helped increase deceased donor grafts participation to up to $79.2 \%$ of transplants (Table 1). 
With 6,284 kidney transplants performed in 2019, the Brazilian transplant program is considered the world's second largest, behind only the US, with more than 22,000 kidney transplants performed annually, most of them with private funding ${ }^{6}$. The Brazilian transplant program's success is the result of many factors, but efforts were focused on the use of deceased donor grafts in the last years (Figure 1). Moreover, both patient and graft survival have also been steadily improving as a result of a consolidated national program, improved surgical technique, advances in immunosuppressive therapy, and transplant centers' efforts. According to the Brazilian Transplant Registry, patient survival is $97 \%$ and $94 \%$ at 1 and 5 years, living donor graft survival is $93 \%$ and $85 \%$, and deceased donor graft survival is $85 \%$ and $72 \%$, respectively ${ }^{6}$.

Despite the satisfactory results achieved, one of the great challenges Brasil has to face is its regional and economic disparities. Brasil has 131 active centers distributed in 22 of its 27 federative units. However, the transplant rate reaches $36.1 \mathrm{pmp}$ in the Southern region, whereas the Northern region has the lowest performance, with $3.7 \mathrm{pmp}$. Some Northern states do not even have an active transplant program, which forces patients living in those states to travel long distances to access the transplant program. The national estimated need for kidney transplantation is still 2 times higher than its annual performance (60 pmp versus 30.1 pmp performed in 2019) ${ }^{6}$.

To improve results, benefits of transplantation must be widespread among the population, as well as the safety and suitability of the Brazilian program,
TABLE 1. HISTORICAL NUMBER OF LIVING AND DECEASED DONOR KIDNEY TRANSPLANT IN BRASIL (1964-2018).

\begin{tabular}{|c|c|c|c|c|}
\hline Period & LD, $n(\%)$ & $\mathrm{DD}, \mathrm{n}(\%)$ & Total & $\begin{array}{l}\text { Accu- } \\
\text { mulated }\end{array}$ \\
\hline 1964-1978 & $913(78.1 \%)$ & $256(21.9 \%)$ & 1,169 & 1,169 \\
\hline 1979-1983 & $1,569(88.6 \%)$ & $202(11.4 \%)$ & 1,771 & 2,940 \\
\hline 1984-1988 & $3,095(80.0 \%)$ & $773(20.0 \%)$ & 3,868 & 6,808 \\
\hline 1989-1993 & $3,922(59.6 \%)$ & $2,656(40.4 \%)$ & 6,578 & 13,386 \\
\hline 1994-1998 & $4,742(52.6 \%)$ & 4,271 (47.4\%) & 9,013 & 22,399 \\
\hline 1999-2003 & $8,600(58.7 \%)$ & $6,037(41.3 \%)$ & 14,637 & 37,036 \\
\hline 2004-2008 & $8,744(50.0 \%)$ & $8,728(50.0 \%)$ & 17,472 & 54,508 \\
\hline 2009-2013 & $7,960(32.0 \%)$ & $16,892(68.0 \%)$ & 24,852 & 79,360 \\
\hline $2014-2018$ & $5,947(20.8 \%)$ & $22,682(79.2 \%)$ & 28,629 & 107,989 \\
\hline
\end{tabular}

LD: living donor; DD: deceased donor; n: number.

in which there is no organ trafficking. Strategic measures in health professional training, adequate reimbursements of transplant centers, and clinical research funding are essential to continue expanding the number and quality of transplants in Brasil. Nevertheless, in the face of the current pandemic caused by SARS-CoV-2, many transplant centers in Brasil and other countries have suffered a noteworthy impact, with the need for major physical and logistical restructuring. The pandemic burden has not yet been clearly estimated, but ABTO and transplant leaders in Brasil make a great effort to keep the Brazilian transplant system alive and in operation.

\section{Contributions}

RDF, JOMP, HTSJ (Writing and proofreading)
FIGURE 1. EVOLUTION OF KIDNEY TRANSPLANTS IN BRASIL (1978-2018)

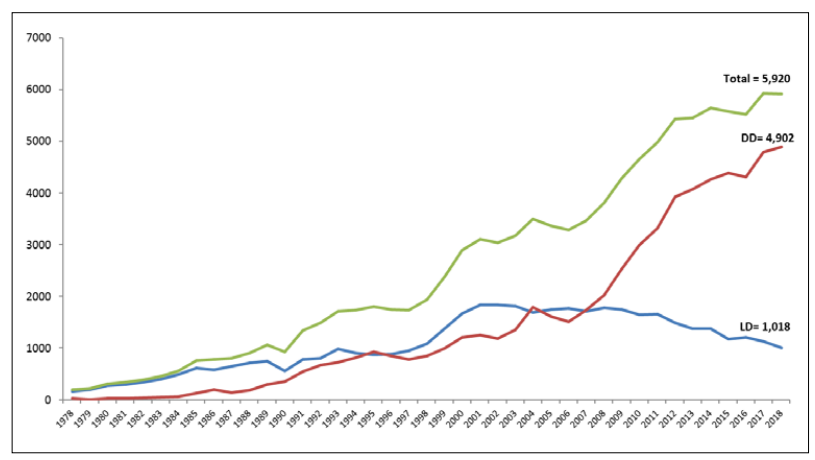

LD: living donor; DD: deceased donor.

\section{REFERENCES}

1. Vasconcelos MSF, Menezes PA, Menezes JAV. O transplante renal no Hospital dos Servidores do Estado - Rio de Janeiro. Revisão de 380 transplantes. JBT J Bras Transplantes. 1998;1:71-83.

2. Merril JP, Murray JE, Harrison JH, Guild WR. Successful homotransplantation of human kidney between identical twins. JAMA. 1956;160(4):277-82.

3. Martins SBS, Ferreira BA, Gonçalves VAC, DeMarco, R, DeLima, MG, Medina-Pestana, JO, et al. Kidney allocation system for Transplantation in Brasil. Curr Transpl Rep. 2019;(6):209-213.

4. Medina-Pestana JO, Galante NZ, Tedesco-Silva Jr H, Harada KM, Garcia VD, Abbud-Filho M, et al. Kidney transplantation in Brasil and its geographic disparity. J Bras Nefrol. 2011;33(4):472-84.

5. Medina-Pestana JO. Organization of a high-volume kidney transplant program: the "assembly line" approach. Transplantation. 2006;81(11):1510-20.

6. Associação Brasileira de Transplante de Órgãos. Dimensionamento dos transplantes no Brasil e em cada estado (2012-2019). Registro Brasileiro de Transplantes. 2019;25(4):1-104. 